\title{
Histological and Immunohistochemical Study on the Possible Therapeutic Role of Stem Cells and Curcumin in Cyclophosphamide- Induced Cardiotoxicity in Adult Male Albino Rat
}

\author{
Omayma K. Helal ${ }^{\mathrm{a}}$, Hala G. Metwaly ${ }^{\mathrm{b}}$, Maha M. Abo Gazia ${ }^{\mathrm{c}}$, Ola M. Mohamed ${ }^{\mathrm{a}}$, Azza I. Helal ${ }^{\mathrm{c}}$
}

a

Department of histology and cell biology, Benha faculty of medicine, $\mathrm{b}_{\text {department }}$ of clinical pathology, Cairo university , c department of Histology, Benha faculty of medicine, kafr sheikh university, Egypt

\section{Correspondence to:}

Azza I. Helal, Histology department, faculty of medicine, kafr sheikh university, Egypt

Email:

azza.helal2016@gmail.com

Received:

Accepted:

\begin{abstract}
:
Introduction: Cyclophosphamide (CP) is used as a chemotherapeutic and an immunosuppressive agent. $\mathrm{CP}$ is known to cause multiple organ toxicity; the most obvious is cardiotoxicity. Aim: Possibile therapeutic effect on bone marrow -derived mesenchymal stem cells (BM-MSCs) in ameliorating CP- induced cardiotoxicity compared with Curcumin in albino rats. Methods: Fifty male albino rats were divided into five groups: group I received intraperitoneal injection of sterile water; group II received oral curcumin $(200 \mathrm{mg} / \mathrm{kg})$; group III received only one intraperitoneal injection of CP (200 mg/kg) and were sacrificed on day 40; group IV received the same treatment as group III followed by oral administration of curcumin from day 10 and were sacrificed on day 40; group $\mathrm{V}$ received the same treatment as group III followed by a single BM- MSCs injection intraperitoneally at a dose of $1 \times 10^{6}$ cells/ rat on day 10 and were sacrificed on day 40. Results: Histological structure of the cardiac muscle by light and electron microscopic examination revealed marked structural changes in rats treated with $\mathrm{CP}$ alone. Improvement in BM-MSCs group more than curcumin treated group was observed. Immunohistochemical staining of the cardiac muscle showed strong positive immunoreactivity for caspase-3 in group III compared to the control and other groups. Also, BM-MSCs extensively reduced the amount of collagen fibers compared with other groups. Conclusion: The use of curcumin has a limited beneficial effect on the protection of cardiac muscle against $\mathrm{CP}$ toxicity compared with stem cells.
\end{abstract}

Keywords: Cardiotoxicity; Cyclophosphamide; stem cells ; Curcumin. 


\section{Introduction}

Cardiotoxicity is a serious adverse effect of chemotherapeutic agents [1]. Cardiomyocytes have a limited mitotic capacity that cannot support its self-renewal [2].

Cyclophosphamide is an alkylating agent with potent antineoplastic and immunosuppressive properties and possibly the most widely used antineoplastic agent [3].

The metabolism of anti-cancer drugs can lead to more active anti-cancer metabolites but those metabolites can likewise contribute to the observed cardiotoxicity [4].

Bone marrow-derived mesenchymal stem cells (BM-MSCs) are considered the most routinely used in clinical studies because they are easily accessible and are routinely collected from adults without the ethical concern inherent to fetal embryonic tissues $[5,6]$.

Curcumin has been reported to exhibit a strong antioxidant property and acts as a scavenger of free oxygen radicals [7].

This study aimed to assess the possible protective role and ameliorating effects of $\mathrm{BM}$ -MSCs compared with curcumin against cyclophosphamide- induced cardiotoxicity histologically and immunohistochemically.

\section{Materials and methods}

\section{Drugs used}

- Cyclophosphamide (Endoxan vials; Baxter Company, Deerfield, IL, USA) was obtained as vials. Each vial contained $200 \mathrm{mg}$ of $\mathrm{CP}$ in dry lyophilized powder form. CP was injected at a dose of $200 \mathrm{mg} / \mathrm{kg}$ [8]. The content of one vial was dissolved in 10 $\mathrm{ml}$ of sterile water to obtain a concentration of $20 \mathrm{mg} / \mathrm{ml}$ for immediate injection. Each rat weighing $200 \mathrm{~g}$ was injected with $2 \mathrm{ml}$ of CP.

- Curcumin is available in the market in the form of powder. The dose used in this study was $200 \mathrm{mg} / \mathrm{kg}$ orally [9]. The powder was dissolved in $400 \mathrm{ml}$ of sterile water to obtain a concentration of $40 \mathrm{mg}$ curcumin $/ \mathrm{ml}$.

- BM-MSCs were prepared in the Department of Medical Biochemistry, Kasr Al-Ainy Faculty of Medicine, Cairo University. They were provided as first-passage culture cells suspended in PBS at a dose of $1 \times 10^{6}$ cells/ rat [8].

\section{Animals}

50 albino rats, their weights ranged between 150 and 200 grams, were divided into five groups (10 rats each)

Group I (control): Each rat in this group was intraperitoneally injected once with $2 \mathrm{ml}$ sterile water and sacrificed after 10 days. 
Group II (curcumin-treated): Each rat received $1 \mathrm{ml}$ of the dissolved curcumin powder orally through gastric gavage once daily and sacrificed after 10 days. Group III (CP-treated): Each rat received a single intraperitoneal injection of $2 \mathrm{ml}$ of dissolved $\mathrm{CP}$ on the first day of the experiment and were sacrificed on day 40. Group IV (CP plus curcumin): Each rat received a single intraperitoneal injection of $\mathrm{CP}$ on the first day of the experiment, followed by oral administration of curcumin from day 10 of the experiment and were sacrificed on day 40 . Group V (CP plus BM-MSCs): Each rat received a single intraperitoneal injection of dissolved $\mathrm{CP}$ on the first day of the experiment, followed by a single dose of BMMSCs, injected intraperitoneally on day 10 of the experiment and were sacrificed on day 40 .

This is a case control study which took place in Kasr Al-ainy, faculty of medicine, Cairo University for 40 days from November, 2017 to December, 2017 after being approved by the Local Ethics Committee of the Faculty of Medicine, Cairo University.

\section{Preparation of bone marrow-derived mesenchymal stem cells:}

Bone marrow was harvested by flushing the tibiae and femora of three 6-weeks-old male Sprague-Dawley albino rats with Dulbecco's modified Eagle's medium supplemented with $10 \%$ fetal bovine serum. Nucleated cells were isolated and resuspended in complete culture medium supplemented with $1 \%$ penicillin-streptomycin [10]. The cells were incubated at $37^{\circ} \mathrm{C}$ in $5 \%$ humidified $\mathrm{CO} 2$ for 12 - 14 days as primary culture. BM-MSCs were distinguished from other BM cells by their tendency to adhere to tissue culture plastic flasks [11]. When they developed (80-90\% confluence), the cultures were washed twice with PBS and the cells were trypsinized with $0.25 \%$ trypsin for $5 \mathrm{~min}$ at $37^{\circ} \mathrm{C}$.

After centrifugation, the cells were resuspended in serum-supplemented medium and incubated in a culture flask. The resulting culture was referred to as first-passage culture [12]. The second exchange of medium was done after 6 days when spindle shaped cells appeared with long processes and vesicular nuclei [13].

The hemocytometer was used to determine the total cell count and assess viability of the cells [14]. BM-MSCs in culture were characterized by their adhesiveness and fusiform shape BM-MSCs in culture were characterized by their adhesiveness and fusiform shape under a phase-contrast microscope.

- At the time of injection, the cells were labeled with a PKH26 dye supplied by 
Sigma, Darmstadt, Germany (PKH26 dye stock, 1 vial containing $>0.1 \mathrm{ml}, 1 \times 10^{-3}$ $\mathrm{M}$ in ethanol\&Diluent $\mathrm{C}$, an iso-osomotic aqueous solution). Their homing in the cardiac tissue was confirmed by immunofluorescence [16] (Fig. 1).

\section{Histological and immunohistochemical study:}

The heart of each rat was taken immediately and divided into two specimens.

One was fixed in $10 \%$ formalin saline solution and was processed to get paraffin sections:

Serial sections of 3-4 microns thickness were cut, mounted on slides and subjected to the following stains:

1) $\mathbf{H} \& \mathbf{E}$ stain for general histological examination [17].

2) Mallory's trichrome stain for detection of collagen fibers [18].

3) Immunohistochemical Staining for caspase -3 antibody (ready- to -use for IHC, catalog code: PA5-23921) using the avidin-biotin-peroxidase complex technique. The primary antibody was a rabbit polyclonal antibody (Thermo Fisher scientific, USA). The dilution used was 1:50 [19\&20]. The sections were examined with light microscope and Negative controls were prepared by omitting the primary antibody. Positive tissue control was performed by applying the previous technique in the same way on duodenal specimen (mybiosource.com).

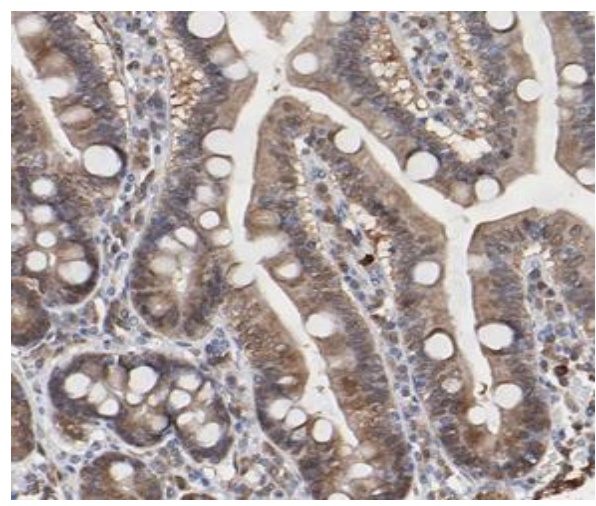

(caspase- 3 immunostaining x 400)

The other specimen was immediately cut into small pieces in all dimensions and fixed in $2.5 \%$ buffered glutaraldehyde and was used to prepare ultrathin sections for electron microscopic examination [21].

\section{Morphometric study}

The mean area percentage of collagen fibers in Mallory's trichrome-stained sections as well as caspase -3 was measured in 10 non over-lapping high power fields for each animal. Appropriate measurements were taken using the image analyzer computer system (Leica Qwin 500C, Leica, London, UK) [22].

\section{Statistical analysis}

The following parameters were expressed as mean $\pm \mathrm{SD}$ :

(1) Area percentage of collagen fibers in Mallory's trichrome-stained sections.

(2) Area percentage of caspase-3 immunoreaction. 
The statistical analysis was carried out using one-way ANOVA analysis of variance for comparison between the different groups, using SPSS (version 16; SPSS Inc., Chicago, Illinois, USA). $\mathrm{P}$ values of 0.05 or less were accepted as statistically significant [8].

\section{Results}

\section{Histological results}

\section{Group I (control)}

$H \& E$ stained sections showed the normal histological structure of cardiac myocytes that appeared arranged in a linear array that branch and anastomose with acidophilic sarcoplasm and oval, centrally located nuclei (Fig.2 a \& b). Mallory's trichrome-stained sections showed minimal basophilic collagen fibers surrounding the cardiomyocyte bundles (Fig.2 c). Weak positive immunoreactivity for caspase -3 was observed (Fig.2 d). Ultrastructural examination of ultrathin sections showed the sarcomeres that were bounded on each side by a Z-line with a central dark A-band and two light I-bands in the periphery. A pale H-zone could be seen in the center of A-band bisected by M-line (Fig.2 e\&f).

\section{Group II (curcumin treated)}

The same structural and ultrastructural results as group I were observed (Fig.3 a,b,c\&d).

\section{Group III (CP treated)}

H\&E stained sections revealed that most of the cardiac muscle fibers were disorganized and lost the normal architecture. Extensive mononuclear cellular infiltrate and diffuse interstitial hemorrhage were also seen. (Fig.4 a \& b).

Mallory trichrome stain exhibited strong accumulation of collagen fibers (Fig.4 c) and intense caspase-3 immunoreactivity was seen (Fig.4 d). Ultrastructural examination revealed disturbance of the normal architecture with destruction of myofibrils. Mitochondria appeared swollen with disrupted crista with nuclear indentation (Fig. 4 e\&f)

\section{Group IV (CP plus curcumin)}

H\&E stained sections showed mild restoration of the normal myocardial structure with congestion of blood vessels (Fig.5 a \&b). Mallory's trichrome-stain showed mild accumulation of collagen fibers (Fig.5 c). Weak positive immunoreaction for caspase -3 was detected (Fig. 5 d). Ultrastructural examination revealed incomplete recovery of the structural loss with mitochondrial swelling and interstitial hemorrhage. (fig.5 e).

\section{Group V (CP plus BM-MSCs)}

H\&E stained sections showed nearly complete restoration of the normal histological structure. Few myocardial cells exhibited focal sarcoplasmic vacuolation without obvious nuclear changes together 
with normal blood vessels and obvious intercalated discs (Figs.6 a\&b). Mallory 's trichrome -stain showed mild accumulation of collagen fibers (Fig.6 c). Weak positive immunoreactivity for caspase -3 was encountered (Fig.6 d). Ultrastructural examination revealed obvious amelioration of the degenerative changes. The mitochondria regained their normal linear interposition between the myofibrils with well defined oval or rounded contour. (fig. 6 e\&f).

\section{Statistical results:}

Table (1): The mean area $\%$ of collagen fibers in all experimental groups.

\begin{tabular}{cccc}
\hline Groups & Mean & $\begin{array}{c}\text { Standard } \\
\text { deviation }\end{array}$ & Significance \\
\hline Group I & & .66583 & G3 \\
& & G4 \\
Group II & .7333 & .49329 & G5 \\
& & & G4 \\
Group III & \multirow{2}{*}{38.9000} & \multirow{2}{*}{2.77308} & G5 \\
& & & G5 \\
& & & G6 \\
Group IV & \multirow{2}{*}{14.2667} & 1.26623 & G2 \\
& & & G3 \\
& & & G5 \\
& & & G6 \\
Group V & \multirow{2}{*}{3.3333} & .92916 & G3 \\
& & & G5 \\
& & & G6
\end{tabular}

Table (2): The mean area $\%$ of positive immunoreactivity for caspase -3 in all experimental groups.

Histogram (1): The mean area $\%$ of collagen fibers in all experimental groups

\begin{tabular}{cccc}
\hline Groups & Mean & $\begin{array}{c}\text { Standard } \\
\text { deviation }\end{array}$ & Significance \\
\hline Group I & .7500 & .55000 & $\mathrm{G} 3$ \\
& & & $\mathrm{G} 4$ \\
GroupII & .8333 & .30551 & $\mathrm{G} 3$ \\
& & & $\mathrm{G} 4$ \\
& & & $\mathrm{G} 5$ \\
& & & $\mathrm{G} 1$ \\
Group III & 31.3333 & .3 .21455 & $\mathrm{G} 2$ \\
& & & $\mathrm{G} 3$ \\
& & & $\mathrm{G} 5$ \\
& & & $\mathrm{G} 6$ \\
Group IV & \multirow{2}{*}{1.0000} & 1.00000 & $\mathrm{G} 1$ \\
& & & $\mathrm{G} 2$ \\
& & & $\mathrm{G} 3$ \\
& & & $\mathrm{G} 5$ \\
Group V & 3.0000 & 1.00000 & $\mathrm{G} 6$ \\
& & & $\mathrm{G} 3$ \\
& & & $\mathrm{G} 5$ \\
\hline
\end{tabular}




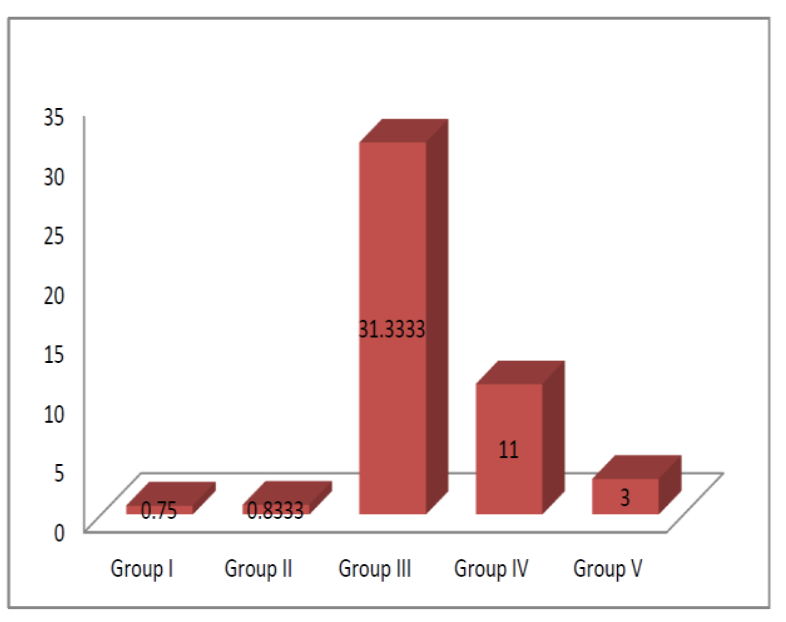

Histogram (2): The mean area $\%$ of positive immunoreactivity for caspase -3 in all experimental groups.
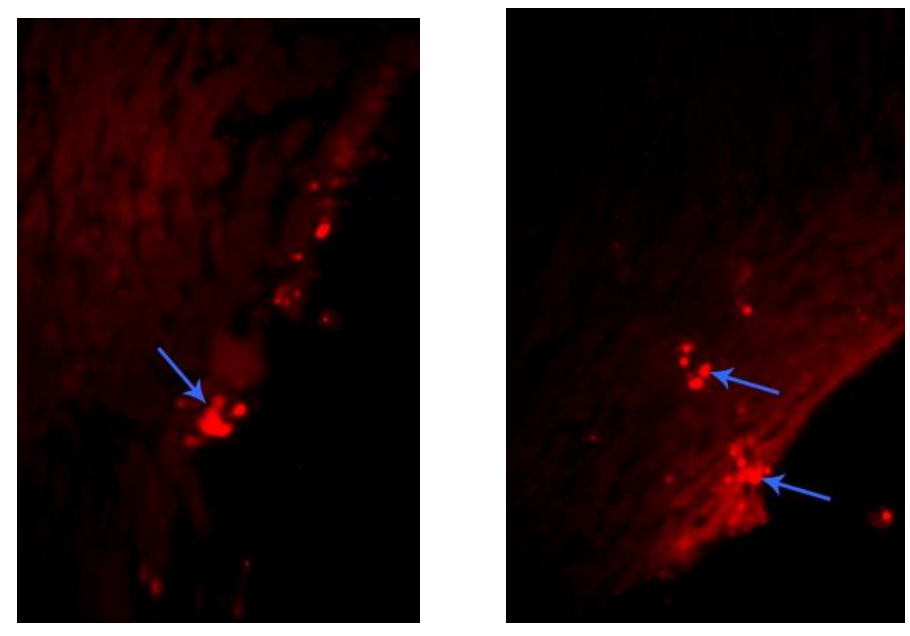

Fig. 1 :A photomicrograph of a section of a rat heart showing positive red immunofluorescent MSCs labelled with PKH26 fluorescent dye (arrows) (PKH26 immunofluorescence x400) 


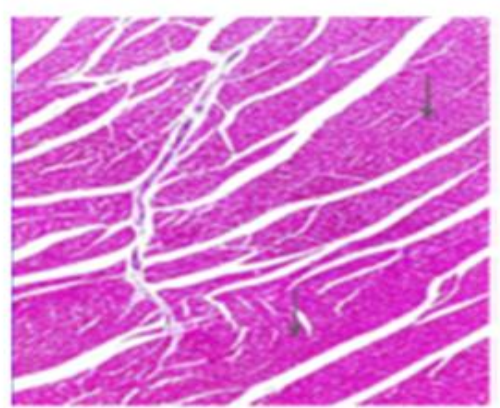

$2 a$

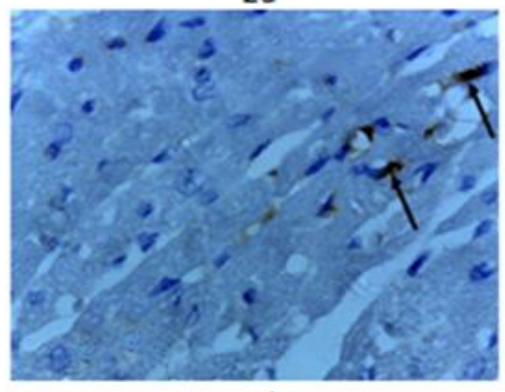

$2 d$

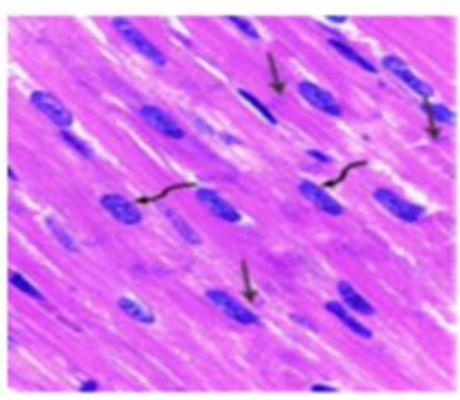

$2 \mathrm{~b}$

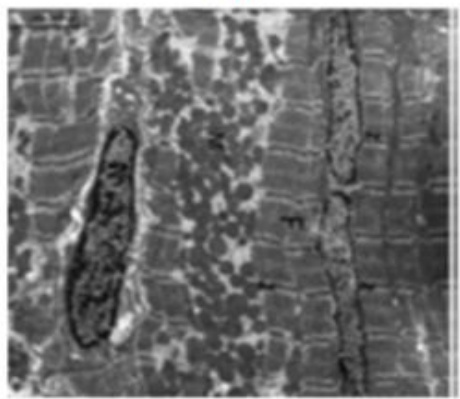

$2 e$

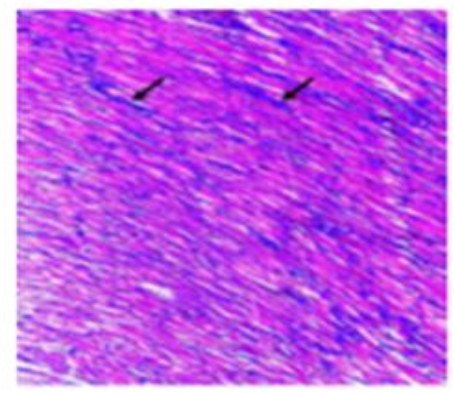

$2 c$



$2 f$

Fig. 2: Photomicrographs of sections of the rat myocardium from control group (group I) showing: (a) branched cardiac muscle fibers with acidophilic sarcoplasm $(\rightarrow)$. (b) centrally located oval nucleus (wavy arrow) and intercalated disc $(\rightarrow$ ). (c) Minimal amount of collagen fibers $(\rightarrow)$. (d) Weak sarcoplasmic caspase -3 immunoreaction $(\rightarrow$ ). (e) An electron micrograph of a section of cardiac muscle showing a central euchromatic nucleus $(\mathrm{N})$ with prominent nucleolus (nu), parallel arrangement of myofibers $(\mathrm{F})$, the mitochondria $(\mathrm{M})$ arranged in rows between them and regularly arranged sarcomeres between $\mathrm{Z}$ lines $(\mathrm{Z})$. (f) regular arrangement of the myofibrils (F) with sarcomeres between $\mathrm{Z}$ lines $(\mathrm{Z})$. Notice: H zone $(\mathrm{H})$ bisected by M line $(\mathrm{M})$. [H\&E, (a) $\times 200 /(\mathrm{b}) \times 1000$; Mallory's trichrome, (c) $\times 200$; caspase -3 immunostaining, (d) $\times 1000$; electron micrographs, (e) x 5800/(f) 17500].

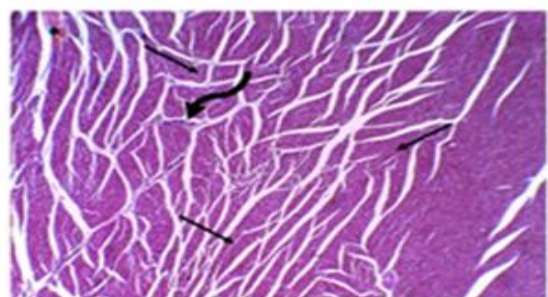

$3 a$

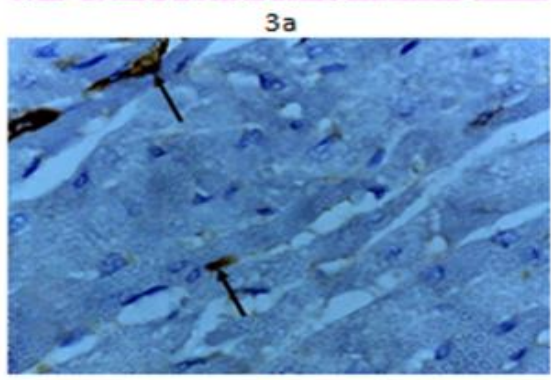

$3 c$



$3 \mathrm{~b}$

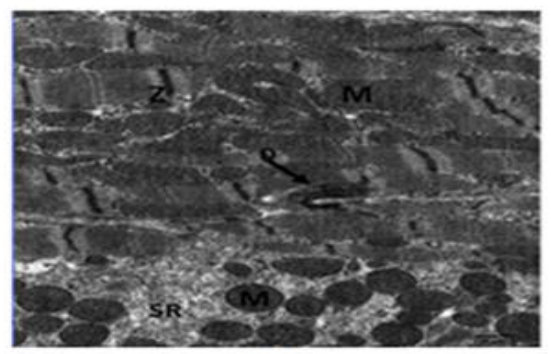

$3 d$

Fig. 3: Photomicrographs of sections of rat myocardium from group II (curcumin-treated) showing: (a) branched cardiac muscle fibers with acidophilic sarcoplasm $(\rightarrow$ ) with blood vessels in between (wavy arrow). (b) Minimal collagen fibers $(\rightarrow)$. (c) Weak sarcoplasmic caspase -3 immunoreaction $(\rightarrow)$. (d) An electron micrograph showing parallel arrangement of myofibers $(\mathrm{F})$ and the mitochondria $(\mathrm{M})$ in rows between them in association with smooth endoplasmic reticulum( SR). 
Notice: the regularly arranged Z- lines (Z) and the continuous intercalated disc (D). [H\&E, (a) $\times 200$; Mallory's trichrome (b) $\times 400$; caspase -3 immunostaining, (c) $\times 1000$; electron micrographs, (d) $\times 5800]$.
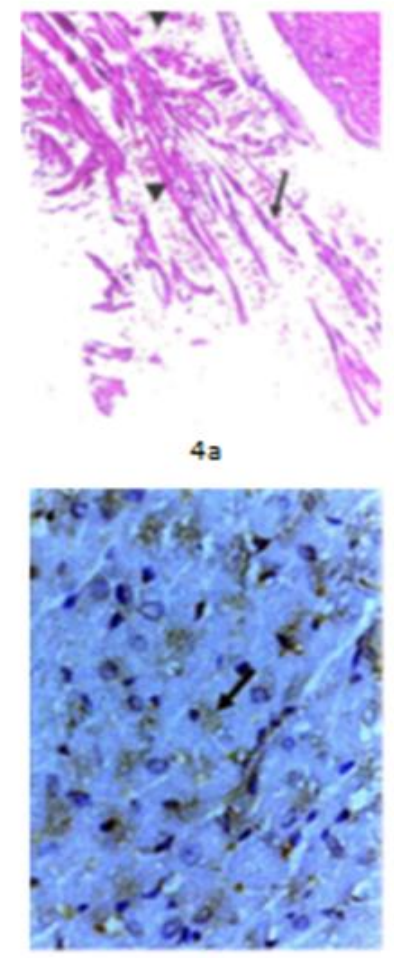

$4 d$

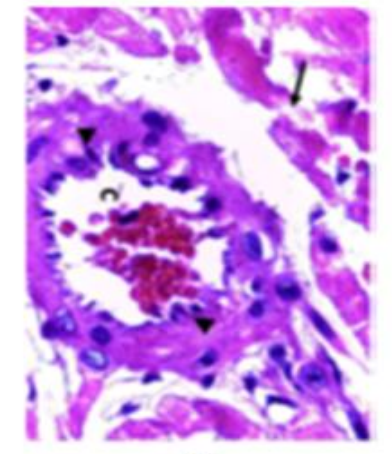

$4 b$

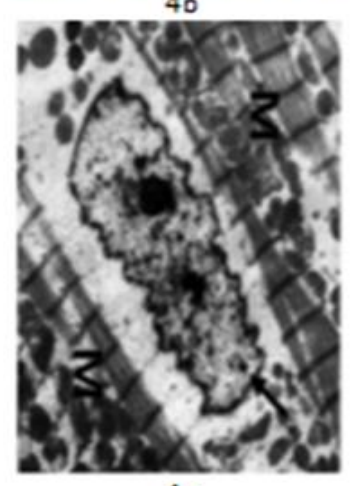

4 e

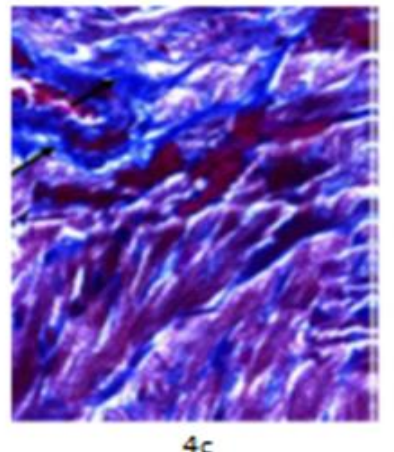

$4 c$

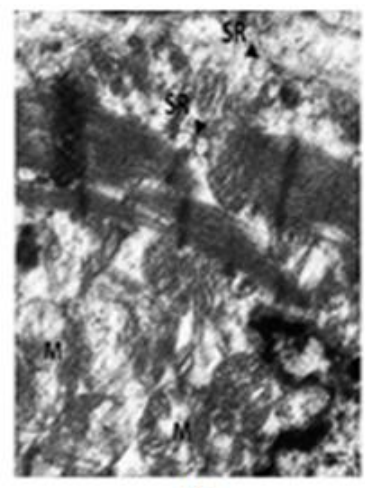

$4 f$

Figure 4: Photomicrographs of sections of rat myocardium from group III showing: (a) fragmentation and disorganization of the cardiac muscle fibers $(\rightarrow)$ and interstitial hemorrhage $(\boldsymbol{)})$. (b) congested blood vessels [C] and perivascular inflammatory infiltrate $(\rightarrow)$ were observed. (c) Accumulation of large amount of collagen fibers $(\rightarrow)$ ). (d) Intense sarcoplasmic caspase -3 immunoreactivity $(\rightarrow)$. (e) An electron micrograph showing degenerated mitochondria with disrupted cristae $(\mathrm{M})$ and indented nucleus with irregular outlines $(\rightarrow)$.(f) degenerated mitochondria(M) with dilated SR ( ). [H\&E, (a) $\times 200 /($ b) $\times 1000$; Mallory's trichrome, (c) $\times 1000$; caspase -3 immunostaining, (d) $\times 1000$; electron micrograph $(e) \times 17500 /(f) \times 20000]$.
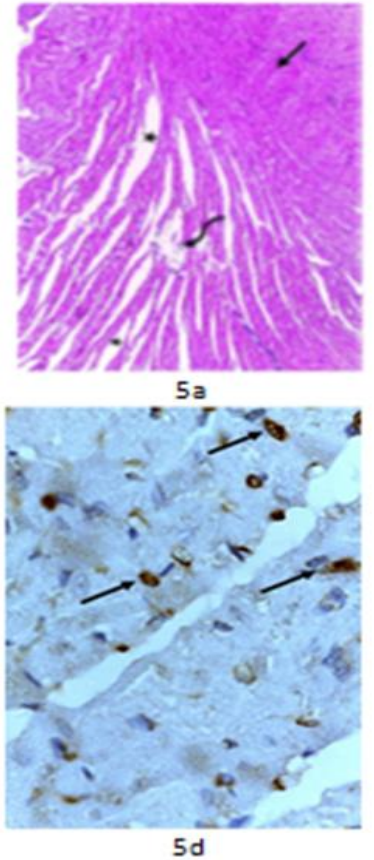

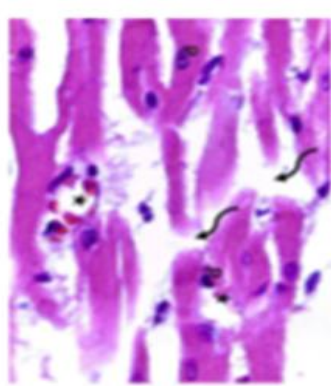

$5 b$

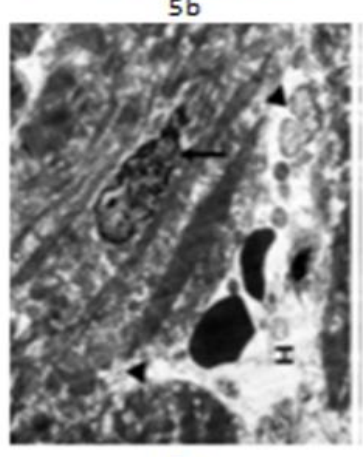

$5 e$

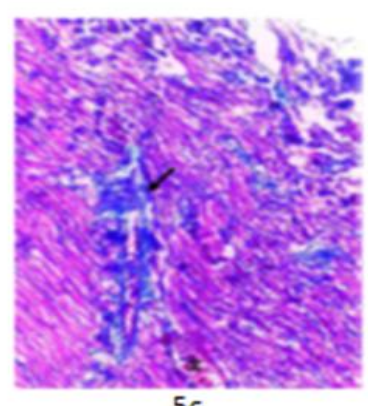

$5 c$ 
Figure 5: Photomicrographs of sections of rat myocardium from group IV showing (a) prominent fibrillolysis (wavy arrow) and widely spaced cardiac muscle fibers (star), disorganized wavy cardiac muscle fibers $(\rightarrow)$. (b) splitting of the fibers (wavy arrow), pyknotic nuclei (P) and congested blood vessel (star). (c) moderate amount of collagen fibers in between cardiac muscle fibers $(\rightarrow)$. (d) moderate sarcoplasmic caspase -3 immunoreactivity. (e) An electron-micrograph showing nuclear indentation $(\rightarrow)$, areas of fibrillolysis $(\longrightarrow)$ and interstitial hemorrhage $(\mathrm{H})$. [H\&E, (a) $\times 200 /($ b) $\times 1000$; Mallory's trichrome, $(\mathrm{c}) \times 400$; caspase -3 immunostaining, $(\mathrm{d}) \times 1000$; electron-micrograph $(\mathrm{e}) \times 5800]$.
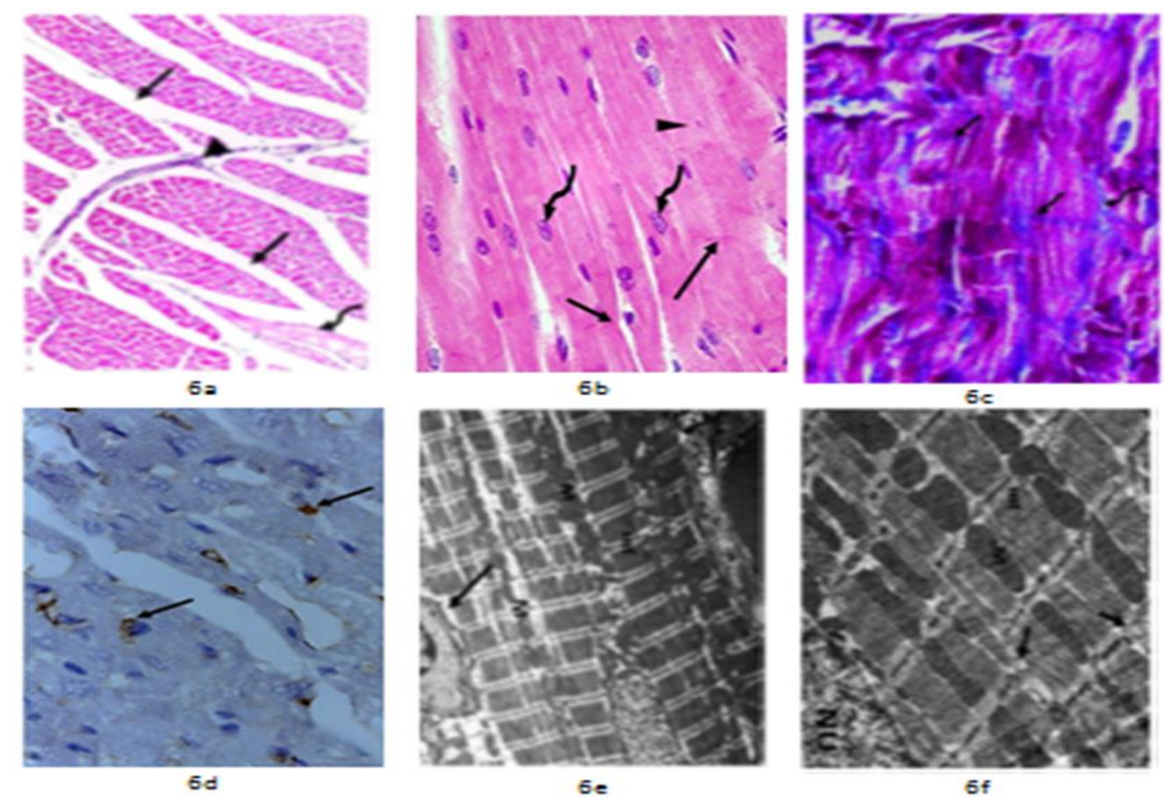

Figure 6: Photomicrographs of sections of rat myocardium from group V showing (a) nearly complete restoration of the normal histological structure with apparently widely spaced muscle fibers $(\rightarrow)$ with blood vessels in-between $(\triangleright)$ and sarcoplasmic vacuolation (wavy arrow). (b) apparently normal intercalated discs $(\rightarrow$ ) and central oval nucleus (wavy arrow). (c) Mild amount of collagen fibers (arrows). (d) weak sarcoplasmic caspase -3 immunoreactivity $(\rightarrow$ ). (e) An electron-micrograph showing more or less well organized myofibrils $(\mathrm{mf})$, normal mitochondria $(\mathrm{M})$ with apparently normal blood vessel $(\rightarrow)$. (f) showing a normal euchromatic nucleus $(\mathrm{Nu})$ with dilated smooth Endoplasmic Reticulum $(\rightarrow)$ and mitochondria $(\mathrm{M})$ arranged between myofibrils (mf). [H\&E, (a) $\times 200 /($ b) $\times 1000$; Mallory's trichrome, $($ c) $\times 1000$; caspase -3 immunostaining, (d) $\times 1000$; electron-micrograph (e) $\times 5800 \&$ (f) $\times 17500$ ].

\section{Discussion:}

Cyclophosphamide (CP) is a widely used drug in cancer chemotherapy and immunosuppression, which could cause toxicity of the normal cells due to its toxic metabolites. The major limitation of $\mathrm{CP}$ is the injury of normal tissue, leading to multiple organ toxicity $[23,24]$.

Cyclophosphamide itself is not cardiotoxic, it is rather the $\mathrm{CP}$ metabolites that induce cardiotoxicity through increasing free oxygen radicals and the decrease in the antioxidant defense mechanisms [25].
Oxidative stress has been widely shown to regulate apoptosis and exerts both agonistic and antagonistic effects on apoptotic signaling [26]. It has been demonstrated to mediate p53dependent cell cycle arrest, DNA repair and apoptosis. [27,28].

Apoptosis was confirmed in the present work by positive caspase 3 immunoreactivity in all $\mathrm{CP}$-injected rats. So, it can be concluded that both apoptosis and necrosis are etiological mechanisms that cause $\mathrm{CP}$ - induced cardiac injury as previously demonstrated by [29].

In the present work, congestion and apparent 
dilatation of the blood vessels as well as interstitial hemorrhages were observed. These observations were consistent with Ghobadi et al (30) who explained these changes to be due to the direct effect of $\mathrm{CP}$ on the vascular endothelial cells leading to release of endothelium relaxation factor-nitric oxide (NO).

Interstitial cellular infiltration observed by light and electron microscopic examination was consistent with Kurauchi et al [31] who reported that $\mathrm{CP}$ triggers induction of cytokines that regulate leukocyte trafficking.

The increase of collagen fibrils in the interstitium of myocardium of $\mathrm{CP}$ treated animals was explained by LHaithloul et al and Borghini et al, [32,33] who reported that systemic and locally produced neurohumoral factors such basic fibroblast growth factor activate fibroblast proliferation and collagen synthesis. During this study electron microscopic examination revealed markedly affected mitochondria that appeared pleomorphic and disarrayed between myofibrils with distorted cristae. These findings were in accordance with several studies $[34,35,36]$ who referred these alterations to disruption of calcium homeostasis and inhibition of $\mathrm{Na}+\mathrm{K}+-$ ATPase that induce mitochondrial swelling secondary to intracellular sodium accumulation.
In the MSC-treated group in the current study, there was reduction in the inflammatory cellular infiltration. $[37,38]$ presumed that MSCs attenuate the self- inflammatory reaction and enhance the anti-inflammatory reaction by regulating the proliferation and differentiation of immunocytes. Cardiomyocytes in this group also showed significant decrease in caspase- 3 reaction. Adiwinata eta 1 [39] have demonstrated that MSCs protect cardiomyocytes from induced apoptosis through release of cytochrome c from the mitochondria.

Significant decrease in collagen fibers accumulation in MSCs treated group compared with $\mathrm{CP}$ treated rats was observed by Mallory trichrome stain and confirmed by statistical analysis which revealed that the mean color area percentage of collagen in MSCs treated group was significantly low and this was concomitant with two studies [40,41]. They mentioned that MSCs exert paracrine antifibrotic effects to attenuate myocardial remodeling through regulation of cardiac fibroblasts (CFB) proliferation. In $\mathrm{CP}+$ Curcumin treated group, there was slight improvement. Curcumin fairly attenuated the interstitial fibrosis; this was in consensus with other studies [42,43]. Curcumin also attenuated cardiomyocyte apoptosis and this was in agreement of Ma et al and Altenburg et al, $[44,45]$ who accused the persistence of 
most of the histological alterations in this group with no evidence of regaining the wellknown picture of the control group to the fact that within limit the cell can compensate for structural derangement. However, persistent or excessive injury causes cells to pass the threshold into irreversible injury.

\section{References}

1- Asiri, Y. A. (2010). Probucol attenuates cyclophosphamide-induced oxidative apoptosis, p53 and Bax signal expression in rat cardiac tissues. Oxidative Medicine and Cellular Longevity, 3(5), 308-316.

2- Curigliano, G., Mayer, E. L., Burstein, H. J., Winer, E., P. \& Goldhirsch, A. (2010). Cardiac toxicity from systemic cancer therapy: a comprehensive review. Progress in cardiovascular diseases, 53(2), 94-104.

3- Ogunsanwo, O. R., Oyagbemi, A.A., Omobowale, T.O., Asenuga, E.R.\& Saba, A.B. (2017). Biochemical and electrocardiographic studies on the beneficial effects of gallic acid in cyclophosphamide-induced cardio-renal dysfunction. J Complement Integr Med. Mar 22.

4- Reis-Mendes, A.F., Sousa, E., de Lourdes Bastos, M.\& Costa, V.M. (2016). The Role of the Metabolism of Anticancer Drugs in Their Induced-Cardiotoxicity. Curr Drug Metab.;17(1):75-90.

5- Rochefort, Y. G., Vaudin, P., Bonnet, N., Pages, J. C\& Charbord, P. \& Eder, V. (2015). Influence of hypoxia on the domiciliation of mesenchymal stem cells after infusion into rats: possibilities of targeting pulmonary artery remodeling via cells therapies?. Respiratory research, 6(1), 125.

6- Forte, G., Minieri, M., Cossa, P., Antenucci, D., Sala, M. \& Prat, M. (2016). Hepatocyte growth factor effects on mesenchymal stem cells: proliferation, migration, and differentiation. Stem cells, 24(1), 23-33.

7- García-Niño, W.R., \& Pedraza-Chaverri, J. (2014): Protective effect of curcumin against heavy metals-induced liver damage. Food and Chemical Toxicology, 69, 182-201.

8- Walaa, M. S. and Laila A. R. (2016). Therapeutic role of bone marrow-derived mesenchymal stem cells in cyclophosphamide-induced cardiotoxicity in adult male albino rat: a morphological and immunohistochemical study. The Egyptian Journal of Histology, 39: 281-293

9- 9 - Chakraborty, M.1., Bhattacharjee \& A.1., Kamath, J.V. (2017). Cardioprotective effect of curcumin and piperine combination against cyclophosphamide-induced cardiotoxicity. Indian J Pharmacol. 2017 Jan-Feb;49(1):65-70

10- 10- Lennon, D.P.\& Caplan, A.I. (2006): Isolation of rat marrow-derived mesenchymal stem cells. Exp Hematol. 2006 Nov;34(11):1606-7.

11- Gnecchi, M. \& Melo, L.G. (2009) .Bone marrowderived mesenchymal stem cells: isolation, expansion, characterization, viral transduction, and production of conditioned medium. Methods Mol Biol. ;482:281-94. doi: 10.1007/978-159745-060-7_18.

12- Shu, W., Qingjian, Z., Sisi, L., Quanjun, Z., Li, L. \& Liangxue, L. (2019). Conversion of embryonic stem cells into extraembryonic lineages by CRISPR-mediated activators. Sci Rep 6, 19648 doi:10.1038/srep19648.

13- Chin, M.H., Mason, M.J., Xie, W., Volinia, S., Singer, M. \& Peterson, C. (2009). Induced pluripotent stem cells and embryonic stem cells are distinguished by gene expression . Cell Stem Cell. 2;5(1):111-23. doi: 10.1016/j.stem.2009.06.008.

14- Miri, A., Hashmani, K., Al-aqaba, M., Faraj, L.A., Fares, U \& Dua, H.S. (2012). The effect of gravitational force on limbal stem cell growth. $\mathrm{Br}$ 
J Ophthalmol. 2012 Jul;96(7):1034-7. doi: 10.1136/bjophthalmol-2012-301624.

15- Kang, E.J., Byun, J.H., \& Park, B.W. (2010). In vitro and in vivo osteogenesis of porcine skinderived mesenchymal stem cell-like cells with a demineralized bone and fibrin glue scaffold. Tissue Eng Part A. ;16(3):815-27. doi: 10.1089/ten.TEA.2009.0439.

16- Nagyova, M., Slovinska, L., Blasko, J., Grulova, I., Kuricova, M. \& Cizkova, D. (2014). A comparative study of PKH67, DiI, and BrdU labeling techniques for tracing rat mesenchymal stem cells. In Vitro Cellular \& Developmental Biology-Animal, 50(7), 656-663.

17- Bancroft . J.D. \& Gamble, M (2008). Theory and Practice of Histological Techniques, $6^{\text {th }}$ Edition, Churchill livingstone, Elsevier, Mosby, Saunders, P.20 200 .

18- Wołuń-Cholewa, M., Szymanowski, K., Andrusiewicz, M., Szczerba, A. \& Warchoł, J.B. (2010): Trichrome Mallory's stain may indicate differential rates of RNA synthesis in eutopic and ectopic endometrium. Folia Histochem Cytobiol. 2010 Jan 1;48(1):148-52.

19- Jantzie, L.L., Tanay, V.I. and Todd, K.G. (2007): Hand book of Neurochemistry and Molecular Neurobiology. Methods in Immunochemistry, $3^{\text {rd }}$ edition, chapter 8, Springer, New York, P. 193 218.

20- Almeida, C., Cardoso, M.F., Sousa, M., Viana, P. \& Barros, A. (2005): Quantitative study of caspase-3 activity in semen and after swim-up preparation in relation to sperm quality. Hum Reprod 20, 1307-1313.

21- Woods, A. \& Stirling, J. (2008): Electron microscopy (30) in theory and practice of histological techniques, (editors: Bancroft, J. and Gamble, M), $6^{\text {th }}$ edition, Churchill livingstone, Elsevier, China, P.600
22- Emsley, R., Dunn, G. \& White, I.R. (2010): Mediation and moderation of exposure effects in randomised controlled trials of complex interventions. Stat Methods Med Res. 2010;19:237-270.

23- De Jonge, M. E., Huitema, A. D., van Dam, S. M., Beijnen, J., H. \& Rodenhuis, S. (2015). Significant induction of cyclophosphamide and thiotepa metabolism by phenytoin. Cancer chemotherapy and pharmacology, 55(5), 507-510.

24- Mythili, Y., Sudharsan, P. T., Selvakumar, E. \& Varalakshmi, P. (2004). Protective effect of DL$\alpha$-lipoic acid on cyclophosphamide induced oxidative cardiac injury. Chemico-biological interactions, 151(1), 13-19.

25- Kurauchi, K., Nishikawa, T., Miyahara, E., Okamoto, Y., \& Kawano, Y. (2017). Role of metabolites of cyclophosphamide in cardiotoxicity. BMC research notes, 10(1), 406.

26- Liu, B., Chen, Y. \& Clair, D. K. S. (2008). ROS and p53: a versatile partnership. Free Radical Biology and Medicine, 44(8), 1529-1535.

27- Chaudhari, M., Jayaraj, R., Bhaskar, A. S. B. \& Rao, P. L. (2009). Oxidative stress induction by T-2 toxin causes DNA damage and triggers apoptosis via caspase pathway in human cervical cancer cells. Toxicology, 262(2), 153-161.

28- Franco, R., Sánchez-Olea, R., Reyes-Reyes, E. M. \& Panayiotidis, M. I. (2009). Environmental toxicity, oxidative stress and apoptosis: menage a trois. Mutation Research/Genetic Toxicology and Environmental Mutagenesis, 674(1-2), 3-22.

29- Todorova, V., Vanderpool, D., Blossom, S., Nwokedi, E., Hennings, L. \& Klimberg, V. S. (2009). Oral glutamine protects against cyclophosphamide-induced cardiotoxicity in experimental rats through increase of cardiac glutathione. Nutrition, 25(7-8), 812-817. 
30- Ghobadi, E., Moloudizargari, M., Asghari, M.H. \& Abdollahi, M. (2017): The mechanisms of cyclophosphamide-induced

testicular toxicity and the protective agents. Expert Opin Drug Metab Toxicol. ;13(5):525-536. doi: 10.1080/17425255.2017.1277205.

31- Kurauchi, K., Nishikawa, T., Miyahara, E., Okamoto, Y., \& Kawano, Y. (2017). Role of metabolites of cyclophosphamide in cardiotoxicity. BMC research notes, 10(1), 406.

32- ALHaithloul, H. A., Alotaibi, M. F., Bin-Jumah, M., Elgebaly, H. \& Mahmoud, A. M. (2019). Olea europaea leaf extract up-regulates Nrf2/ARE/HO-1 signaling and attenuates cyclophosphamide-induced oxidative stress, inflammation and apoptosis in rat kidney. Biomedicine \& Pharmacotherapy, 111, 676-685.

33- Borghini, A., Manetti, M., Nacci, F., BellandoRandone, S., Guiducci, S. \&Weber, E. (2015). Systemic Sclerosis Sera Impair Angiogenic Performance of Dermal Microvascular Endothelial Cells: Therapeutic Implications of Cyclophosphamide. Jun 15;10(6):e0130166. doi: 10.1371/journal.pone.0130166. eCollection

34- Park, J. M., Hahn, S. M., Han, J., W. \& Lyu, C. J. (2018). A Case of Successfully Treated Severe Heart Failure due to Cyclophosphamide Induced Cardiomyopathy. Clin Pediatr Hematol Oncol, 25(1), 71.

35- Iqubal, A., Iqubal, M.K., Sharma, S., Ansari, M.A. \& Haque, S.E. (2019): Molecular mechanism involved in cyclophosphamideinduced cardiotoxicity: Old drug with a new vision. PLife Sci. 1;218:112-131. doi: 10.1016/j.lfs.2018.12.018.

36- El-Agamy, D. S., Elkablawy, M. A. \& AboHaded, H. M. (2017). Modulation of cyclophosphamide-induced cardiotoxicity by methyl palmitate. Cancer chemotherapy and pharmacology, 79(2), 399-409.

37- Rosen, O., Massenkeil, G., Hiepe, F., Pest, S. \& Arnold, R. (2001). Cardiac death after autologous stem cell transplantation (ASCT) for treatment of systemic sclerosis (SSc): no evidence for cyclophosphamide-induced cardiomyopathy. Bone marrow transplantation, 27(6), 657.

38- Rog-Zielinska, E. A., Norris, R. A., Kohl, P. \& Markwald, R. (2016). The living scar-cardiac fibroblasts and the injured heart. Trends in molecular medicine, 22(2), 99-114.

39- Adiwinata Pawitan, J. (2019). Exploring the Most Promising Stem Cell Therapy in Liver Failure: A Systematic Review. Stem Cells Int. 2019 Dec 1;2019:2782548. doi: 10.1155/2019/2782548.

40- Wysoczynski, M., Bolli, R. (2019): A realistic appraisal of the use of embryonic stem cell-based therapies for cardiac repair. Eur Heart J. 2019 Nov 28. pii: ehz787. doi: 10.1093/eurheartj/ehz787.

41- Wen, Z., Zheng, S., Zhou, C., Wang, J. \& Wang, T. (2011). Repair mechanisms of bone marrow mesenchymal stem cells in myocardial infarction. Journal of cellular and molecular medicine, 15(5), 1032-1043.

42- Liu, K., Chen, H., You, Q. S., Ye, Q. \& Lu, Q. (2017). Curcumin attenuates myocardial ischemia-reperfusion injury. Oncotarget, $8(67)$, 112051 .

43- He, Y.C., He, L., Khoshaba, R., Lu, F.G., Cai, C. \& Cao, D. (2019): Curcumin Nicotinate Selectively Induces Cancer Cell Apoptosis and Cycle Arrest through a P53Mediated Mechanism.Molecules.18;24(22). pii: E4179. doi: 10.3390/molecules24224179.

44- Ma, J., Ma, S.Y. \& Ding, C.H. (2017): Curcumin reduces cardiac fibrosis by inhibiting myofibroblast differentiation and decreasing transforming growth factor $\beta 1$ and matrix 
metalloproteinase 9/tissue inhibitor of

metalloproteinase 1. Chinese journal of integrative medicine, 23(5), 362-369.

45- Altenburg, J.D., Bieberich, A.A., Terry, C., Harvey, K.A. \& Siddiqui, R.A. (2011): A synergistic antiproliferation effect of curcumin and docosahexaenoic acid in SK-BR-3 breast cancer cells: unique signaling not explained by the effects of either compound alone. BMC cancer, 11(1), 149.

To cite this article: Omayma K. helal, Hala G. Metwaly, Maha M. Abo Gazia, Ola M. Mohamed, Azza I. Helal. Histological and immunohistochemical study on the possible therapeutic role of stem cells and curcumin in cyclophosphamide-induced cardiotoxicity in adult male albino rat .BMFJ 2020;37(1):193-206 DOI:10.21608/bmfj.2020.22518.1204 